\title{
A guerra como estrutura: sua influência nas relações de poder no final da Idade Média e na Idade Média Tardia
}

\section{Andréa Grion Hungaro*}

DOI: 10.11606/issn.2318-8855.v10i2p721-750

Resumo: Este trabalho tem como objetivo analisar o papel da guerra, assim como sua influência nas relações de poder existentes durante o final da Idade Média e na Idade Média Tardia (séculos XII ao XVIII), por uma perspectiva combinada entre análise historiográfica e estudos de Relações Internacionais (RI). O presente artigo procura compreender as repercussões que a guerra tem, tanto na esfera doméstica quanto internacional, ou seja, de maneira sistêmica. Para que se possa compreender os impactos da guerra é necessário pensar a história através da ideia de longa duração, ou seja, é fundamental levar em conta o predomínio dos costumes, das divisões sociais e de poder, e das estruturas (ainda que com algumas transformações) que caracterizam tal período. Por fim, constata-se uma crítica ao consenso sobre os Tratados de Vestfália como marco que daria início ao Sistema Internacional Moderno.

Palavras-chaves: Idade Média Tardia; Guerra; Relações de Poder; Estrutura; Sistema Internacional; Vestfália 


\section{O poder na Idade Média}

Andréa Grion Hungaro

\section{Introdução}

O período comumente conhecido como Idade Média pode ser caracterizado por diversos espaços e poderes (CORTÁZAR, 2002). Tal período, assim como o que se estende (a Idade Média Tardia), tem as mesmas bases fundamentais - atenta-se ao fato de que a noção de uma "Ionga Idade Média" transcende uma delimitação cronológica tradicional e culmina com o mundo pós revoluções (GOFF, 2014). Tendo em vista tais aspectos, ressalta-se a essencialidade em se pensar tal período através do conceito de Longa Duração, que está estritamente relacionado à noção de estrutura e é relacionada a um tipo de organização/realidades sociais, ou seja, uma articulação utilizada pelo tempo (BRAUDEL, 2007, p.49); nota-se que os modelos utilizados em uma análise têm “(...) duração variável: valem o tempo que vale a realidade que eles registram (...) esse tempo (...) é primordial, porque, mais significativos (...) que as estruturas (...), são seus pontos de ruptura, sua brusca ou lenta deterioração (...)" (BRAUDEL, 2007, p. 68). Ou seja, para compreender melhor determinado período, faz-se necessário observar se houve (e quando) grandes rupturas relativas aos diversos aspectos sociais.

O presente artigo tem como objetivo compreender o papel da guerra nas relações de poder, assim como sua influência sobre as mesmas durante o final da Idade Média e na Idade Média Tardia. Para entender melhor esse vasto período, emprega-se a ideia de longa duração - conceito que possibilita observar o fato de que a divisão clássica entre Idade Média e a Modernidade não teve, na verdade, rupturas drásticas, mas presenciou uma continuidade sistêmica-normativa e epistemológica, especialmente sobre os costumes.

É necessário, portanto, considerar o conceito de poder, assim como 


\section{O poder na Idade Média}

A guerra como estrutura

compreender brevemente a contextualização antecessora do período estudado, para que a junção de ideias utilizadas na análise conjuntural possa abranger a complexidade do período.

Compreende-se que há, na sociedade, instrumentos de integração social (estruturas), caracterizados pelos simbolismos que permitem a existência de certo consenso sobre a ordem social e suas reproduções. As questões estruturais muitas vezes estão relacionadas àqueles que detêm mais poder - é através de tal mecanismo que se legitima a ordem hierárquica e suas distinções (BOURDIEU, 1989). Destaca-se que embora o poder político seja menos caracterizado pela coerção, a utilização força/violência não está de toda ausente - pois se relaciona à afirmação do próprio poder (BALANDIER, 1982).

Ao analisar questões sobre o poder, pode-se mencionar uma das definições clássicas (weberiana) sobre o tema, que apresenta três ideias gerais: "dominação", "poder" e "disciplina" -relacionadas com a ordenação de pessoas (CORTÁZAR apud WEBER, 2002, p.14-15) que podem ser subdivididas. Isso possibilita a interpretação de que as formas e as competências de poder, durante o período analisado, podem ser resumidas em seis: a primeira diz respeito às formas com que as normas de convivência eram ditadas - facilitando as classificações e hierarquias; a segunda se caracteriza pela designação daqueles que controlam o cumprimento das normas garantir os direitos dos titulares do poder (esses, eram ampliados para as esferas supra locais e regionais); a terceira forma de poder é aquela que diferenciava a dominação de seus titulares, exercendo três tipos de capacidade: justiça, competência de milícia e fiscalização; a quarta forma é a disposição de uma imagem de poder (social/de status) que vinculava e englobava, nas relações de poder, a percepção dos costumes como forma de representação hierárquica - havia a existência de 


\section{O poder na Idade Média}

Andréa Grion Hungaro

combinações de hierarquizações, como exemplo, cabe destacar os vínculos: religiosos (distinguia-se, assim, os cristãos), de dependência (senhorial e os de vassalagem); a quinta forma relaciona-se à capacidade de projeção de poder através da materialidade (muito mais associada às grandes construções, como castelos, fortalezas, do que a bens materiais de fato); e por fim, a sexta forma que diz respeito à capacidade de projeção imaterial, assim como a sobrevivência da mesma, na mentalidade social (CORTÁZAR, 2002, p.26-33). Observa-se, portanto, que o poder está relacionado com suas diversas formas, e se encontra vinculado às instituições e estruturas sociais de determinada época (BOURDIEU, 1989).

Para compreender o papel da guerra nas relações de poder, utiliza-se a terceira forma, uma vez que essa permite entender algumas divisões (de poder) existentes, e a segunda capacidade, e mais importante, nesse estudo, pois resume às possibilidades de convocação de uma força militar, ou seja, o reconhecimento de se utilizar e convocar uma força coercitiva, sendo essa composta por vassalos, "fideles"1 e "milites". ${ }^{2}$ Tal característica foi de grande importância e de natureza decisiva durante tal período, pois significou certa separação entre as relações de vassalagem/senhorio e de clientelismo, e que, posteriormente, serviriam como forma de definir os status dos diferentes perfis sociais da cavalaria. (CORTÁZAR, 2002, p.26-28).

\footnotetext{
1 Os "fideles", no mundo laico, eram aqueles que faziam uma prestação de fé através de um juramento sobre as res sacra (Escrituras, a cruz, por exemplo) diante de testemunhas. Assim, um homem colocava-se sob a benevolência de um outro mais poderoso, particularmente no plano político, como promessa de obediência a um soberano ou compromisso solene de proteção dos sujeitos e de engajamento de um guerreiro (FOSSIER, 2002, p. 528).

2 "Os milites eram aqueles que monopolizavam em seu benefício as técnicas e os prestígios militares, não eram somente especialistas de luta, uma vez que se transformaram em uma peça chave da ordem social. No entanto, embora constituíssem, a continuação dos nobres, um verdadeiro grupo aristocrático seguia sendo um meio relativamente aberto para o qual poderiam se juntar todos aqueles (...) capacitados para a atividade militar, independentemente de sua origem e sua situação econômica. " (RICHER apud CONTAMINE, 1984, p.39-40).
} 


\section{O poder na Idade Média}

A guerra como estrutura

Ressalta-se que ai nda os conceitos de poder e dominação estavam estritamente ligados, uma vez que as bases do Ocidente Medieval foram criadas pelas guerras - defensivas (num primeiro momento) e ofensivas. Tendo em vista tais aspectos, é essencial fazer uma breve apresentação do contexto histórico, considerando-se as características gerais apresentadas entre os séculos X e XII. Tal período é, nesse caso, um norte que possibilita obter uma visão mais ampla e clara a respeito da existência ou não de grandes rupturas. Atenta-se ao fato de que esse momento é caracterizado pelo fim dos ataques externos (ocorridos no início do século XI) ao Ocidente Europeu (CONTAMINE, 1984, p.37) - com o cessar do perigo externo, pode-se afirmar que foi abandonada a posição/situação defensiva, fazendo com que as estratégias, a longo prazo, mudassem - aumentando-se os domínios (CONTAMINE, 1984, p.38). Ou seja, uma vez que não era necessário ocupar-se com os conflitos externos, os governos locais passaram a velar pelas questões domésticas. Essa atenção para assuntos internos também é identificada na Idade Média Tardia de Johan Huizinga (2016).

Destaca-se que uma vez que o final da Idade Média e a Idade Média Tardia tinham como característica a expansão europeia, as noções de poder estão essencialmente relacionadas à guerra e à ideia de legitimação (do poder) (CORTÁZAR, 2002, p.17). Nesse sentido, nota-se que havia a coexistência de ordens sócio-políticasjurídicas, que, de maneira geral, eram utilizadas, através dos conflitos, como justificativa para adquirir maior poder. No entanto, Cortázar (2002), assim como outros autores, reconhecem que definições puras e isoladas não são (auto)suficientes para compreender tal momento histórico. Ou seja, os conceitos por si só não são suficientes para a compreensão da complexa conjuntura social, política e econômica. Tendo em vista a grande cronologia estudada, pode-se compreender a guerra como 


\section{O poder na Idade Média}

Andréa Grion Hungaro

estrutura - nota-se que mesmo após tal período houve a manutenção de princípios regentes que justificam a guerra. Pode-se afirmar, portanto, que a legitimação dos conflitos encontra-se, de fato, enraizada. Ou seja, compreende-se que “(...) a guerra foi plenamente integrada ao sistema de valores do ocidente (...)" (FITZ, 2003, p. 224).

Ao contrário de alguns estudiosos que acreditavam que as relações de poder da Idade Média eram um processo aberto, e sobretudo, com estruturas instáveis e incompletas, autores como Jacques Le Goff e Eric Hobsbawm, percebiam as características de tais momentos como um processo de longa duração. Portanto, destaca-se Fernand Braudel, que acredita que as divisões temporais, são, e devem ser marcadas pelas grandes rupturas (e não apenas por suas transformações) (CORTÀZAR, 2002, p.18). Nesse sentido, pode-se destacar que o final da Idade Média, assim como a Idade Média Tardia proveram dois modelos importantes (observados no longo prazo): a ascensão sistêmica das formas de expansão das fronteiras e como aspecto hierárquico social; e a estruturação de uma base institucional, sobretudo, interna para governar (controle de elementos sistêmicos) (MORILLO et al, 2009, p. 219). Tais modelos, ainda que essenciais para as esferas políticas (doméstica e internacional), estavam relacionados à guerra - que passou a ter um caráter sistêmico sócio-militar. De maneira geral, pode-se afirmar que os modelos instaurados, a partir do século XI, prevaleceram, pelo menos, ao longo dos sete séculos seguintes no que diz respeito a “(...) competição - tanto entre diferentes unidades políticas europeias, quanto entre os diversos elementos do sistema político (...)" (MORILLO et al., 2009, p. 219). Tais aspectos contribuíram para o desenvolvimento e a elaboração da militarização dos elementos do sistema, especialmente no que diz respeito à cultura da guerra com a construção dos Estados. Compreende-se, portanto, que “(...) não houve nem um breve momento entre (...) 1050 e 1750 que possa ser identificado (...) 


\section{O poder na Idade Média}

A guerra como estrutura

como um ponto de ruptura (...)" (MORILLO et al, 2009, p. 219).

Tendo em vista o fato de que a guerra foi durante muito tempo baseada em valores e culturas, e que os mesmos se enraizaram socialmente (ainda que mudanças, especialmente, tecnológicas e táticas, tenham ocorrido), é possível compreender que a estrutura formada pela guerra estava vinculada não apenas às formas políticas (de poder), mas também à legitimação das mesmas (MORILLO et al, 2009, p. 219) - nota-se que os aspectos militares (relacionados à expansão de um sistema europeu ocidental) estavam ligados à expansão de valores e, também, as formas de organização interna (como por exemplo jurídicas e sociais. Dessa forma, pode-se afirmar que havia a noção de um sistema (estrutural) sócio-militar europeu esse, combinado a fatores socioeconômicos, permitiu o fortalecimento de bases que fundamentaram a ascensão e a consolidação dos “Estados" (MORILLO et al, 2009, p. 222-223).

Sobre às questões domésticas, atenta-se ao fato de que enfrentamentos e conflitos locais eram, de certo modo, comuns, especialmente nas vilas e cidades, uma vez que poderiam significar e funcionar como marcos de uma reestruturação das relações de poder (níveis locais), mas também, poderiam resultar na determinação da repartição de poderes no âmbito superior (regional ou até estatal). Dessa forma, o papel das guerras - como forma de disputas - é essencial para compreender como tal elemento se constituía como meio para alcançar tanto objetivos materiais como políticos. (GÓMEZ, 2012, p.151).

No âmbito internacional, ao se pensar o período da Idade Média Tardia, tratados como o da "Paz de Vestfália" (acordo entre os "Estados" em 1648 que para as RI marca o início do Sistema Internacional Moderno e a prevalência da paz), de 


\section{O poder na Idade Média}

Andréa Grion Hungaro

caráter multilateral, demonstram a existência de uma complexidade conjuntural implicavam a coexistência de diferentes tipos de alianças políticas, sendo essas verticais ou horizontais (entre iguais ou não) (DEWALD apud ROSHCHIN, 2006, p.603). Nesse sentido, demonstra-se a ideia de que tais momentos históricos eram marcados e afetados, pelos diversos tipos de poderes (muitas vezes respaldados pela ética e estratégica da guerra). Observa-se, contudo, que no final da Idade Média Tardia, houve uma combinação de ideias "modernas" com as bases/fundamentos medievais, ou seja, ainda que estivesse ocorrendo uma maior centralização do poder, não é possível afirmar que isso tenha sido, substancialmente, uma oposição aos poderes relacionados ao medievo - as unidades políticas detinham maior ou menor poder de acordo com a eficácia de controle, ou seja, através dos meios sócio-militares (MORILLO et al, 2009, p. 233) e da legitimação ligadas aos mesmos. Compreende-se, assim, a grande importância que os diferentes níveis e hierarquias sociais, estritamente ligados à guerra e a um sistema organizacional militar, expressavam em relação às questões de poder em tal período.

Destaca-se que o que havia se modificado um pouco diz respeito às formas políticas - no final da Idade Média Tardia, essas se tornaram mais formais e públicas, contudo, ainda era possível observar relações de caráter pessoal. Sendo assim, podese afirmar que uma maior centralização foi, de fato, muito mais abstrata do que concreta. Ou seja, a abstração do "Estado", teve mínima utilidade para aqueles que detinham o poder, especialmente nas soluções de guerras, inimizades e para questões de ordem (ROSHCHIN, 2006, p.604).

Deve-se compreender que, segundo Gómez (2012), o papel da guerra, por estar vinculados às relações de poder (em seus diversos níveis), era responsável por afetar toda a sociedade (suas consequências envolveriam não apenas uma determinada 


\section{O poder na Idade Média}

A guerra como estrutura

ordem); sendo assim, deve-se destacar as relações existentes por vínculos (senhoriais, econômicos e pessoais) - muitos conflitos internos se davam pela vontade de conquistar cargos importantes e status, que se caracterizavam como os instrumentos de poder mais eficazes, por atuarem em diversos níveis, desde o local até o regional. Uma vez que as guerras alteravam as relações sociais, as relações de poder poderiam, também, ser modificadas. As consequências e as possibilidades que os conflitos permitiam, especialmente, de se obter uma posição privilegiada, era um fator decisivo nas relações domésticas de poder.

Ao se pensar a guerra como estratégia para (re)configurar os poderes e vínculos existentes, é necessário observar os incentivos e fundamentos políticos, econômicos e sociais existentes, assim como ter em mente o complexo aparato do(s) "Estado(s)". Ressalta-se, assim, que em tal período o papel das normas e das convenções eram essenciais - asseguravam, especialmente através dos costumes, a coesão social.

O estudo da guerra permite, portanto, interpretar, profundamente, as questões socioculturais (costumes regionais e temporais). Nesse caso, estudar a maneira com que tais conflitos ocorriam, as regras e instituições envolvidas, possibilita uma compreensão muito mais ampla e completa do período (BLACK, 2007, p.1).

\section{Sociedade, cultura e a guerra.}

A guerra é o instrumento que compõe, amplamente, as relações externas, assim como mantém a ordem interna (MORILLO et al, 2009, p. 95); ademais, pode-se relacionar a crescente eficácia militar com os aparatos e mecanismos governamentais e sociais, que estão intrinsecamente ligados às questões/divisões de poder, sobretudo, nas hierarquias. Ao se pensar a guerra como estrutura, deve-se ter em 


\section{O poder na Idade Média}

Andréa Grion Hungaro

mente que questões culturais, como os valores agregados aos eventos, são de extrema importância - permitem analisar os aspectos de poder (em suas semelhanças, diferenças e desafios) internos e externos. (MORILLO et al, 2009, p. 97). Nesse sentido, a ideia comumente associada à Idade Média como fragmentada e de conflitos voltados apenas para o âmbito político-local se mostra incompleta (MORILLO et al, 2009, p. 219).

Para compreender a complexidade do tema no período abordado, deve-se ter em mente que "(...) a guerra medieval foi todo um mundo em si mesma (...)" (CONTAMINE, 1984, vii). É, portanto, fundamental notar e destacar suas autenticidades, tais como: o recrutamento militar, a composição e organização dos exércitos, e as implicações conjunturais das esferas micro e macro nas relações de poder. Ou seja, reforçar os laços existentes que caracterizam a guerra como um fenômeno amplo (CONTAMINE, 1984, vii).

Ao estudar o período medieval (e em especial a Idade Média Tardia), compreende-se que as sociedades da Europa Ocidental, ainda que unidas sob a noção de uma Cristandade, apresentavam complexas relações políticas, sociais e econômicas. Tal complexidade se refletia nas relações entre os "países" e nas relações domésticas de poder - havia, portanto, uma mistura entre as diferentes formas e práticas que caracterizam tal período. Nesse sentido, atenta-se ao fato de que mesmo sem um monopólio do uso da força, não significa dizer que as relações existentes eram totalmente anárquicas ou puramente hierárquicas - existiam relações verticais e horizontais, sendo, respectivamente, as primeiras marcadas pela subordinação e as últimas pela coordenação (TESCHKE, 2006, p. 536).

Para entender a guerra como estrutura, precisa-se ter em mente que a mesma 


\section{O poder na Idade Média}

A guerra como estrutura

não deve ser compreendida somente como um meio utilizado pela política (em especial pelos Estados) - a guerra antecede tais instituições (CLAUSEWITZ apud KEEGAN, 1993) e está extremamente relacionada à cultura. O chamado sistema feudal não era, de fato, algo único e muito menos homogêneo - havia diversas variações tanto em relação ao tempo quanto ao espaço na Europa, permitindo assim que a guerra estivesse quase sempre presente (KEEGAN, 1993).

Ressalta-se que as características socioculturais existentes, relacionadas às guerras têm, como base, a ideia de cavalaria. Dessa forma, mesmo com um período relativamente grande em que se estabelecera a paz, não há quaisquer associações de tal período com uma perda do dinamismo da cavalaria, ou do enfraquecimento de sua força expansiva. Segundo Huizinga (2016), embora houvesse uma idealização, por alguns estudiosos, nem sempre esses valores correspondiam ao que ocorria de fato no mundo político, e sobretudo, nos conflitos.

Sublinha-se, aqui, o importante papel da Igreja, uma vez que essa teve uma influência essencial a respeito das mentalidades de guerra - havia um esforço tanto para exaltar as virtudes de seu exército em ocasiões de guerras, quanto para depurar conflitos entre os povos cristãos (CONTAMINE, 1984, p.40). Nesse sentido, as obrigações dos membros do clero para com o reino também estariam vinculadas à autoridade política, ou seja, embora houvesse alguns conflitos entre os mesmos, compreende-se que tais domínios (espirituais e temporais) não podem caracterizar-se como sociedades distintas governadas por poderes coordenados, mas como "departamentos" separados dentro de uma única sociedade política (dentro da mesma estrutura) à qual os diversos poderes medievais estariam sujeitos (LATHAM, 2019). 


\section{O poder na Idade Média}

Andréa Grion Hungaro

Observa-se que, ainda, durante os séculos XIV e XV havia grande preocupação e interesse político em continuar as Cruzadas, contudo, tais expedições - ainda que pouco concretizadas - não eram a prioridade política, havia uma preocupação com a manutenção da paz e da segurança dos territórios governados (manutenção das relações de poderes, em suas diversas esferas). Compreende-se, assim, que a pouca existência de conflitos internos, especialmente durante o final da Idade Média, e por quase toda Idade Média Tardia, está relacionada a uma forma de diminuir as mortes (especialmente dos exércitos) dentro da própria cristandade, e do reconhecimento por parte dos governantes de territórios soberanos (HUIZINGA, 2016, p.164).

Para melhor analisar tal período e as questões militares, destaca-se as fontes de caráter econômico e administrativo (arquivos de ordem pública e, em menor escala, de ordem privada), que permitiram o conhecimento a respeito dos tipos e modalidades de recrutamento, de serviços e das variações militares (CONTAMINE, 1984). Compreende-se assim, que embora os ideais e valores cavaleirescos tivessem distintas características - da mais moral até a puramente econômica -; a sobrevivência do cavaleirismo não teria sido preservada, como o ideal de vida, se em tais princípios não existisse um caráter social necessário (HUIZINGA, 2016, p.173).

\section{Tipos de Guerra, ordens e divisões sociais.}

Tendo em vista que a guerra estava baseada no ideal e no imaginário dos cavaleiros, assim como se encontrava enraizada na sociedade, é necessário apresentar, primeiramente, os tipos de guerras que havia: guerras justas, guerras santas, guerras defensivas e guerras ofensivas. Ou seja, eram os diferentes tipos de poder, de relações internas e externas, que conduziam tais ações. (LATHAM, 2018).

A guerra pode ser compreendida por suas diversas motivações, e podem ser 


\section{O poder na Idade Média}

A guerra como estrutura

resumidas, de forma geral, em dois caráteres: defensivo e ofensivo. O primeiro tipo pode incluir a necessidade de defender-se de uma agressão, o instinto de sobrevivência, ou até a resistência perante um invasor, tirano ou quaisquer possíveis perturbações à ordem e paz; já o último, é relacionado à incitação de violência ao "outro", à dominação, e, principalmente, à imposição de modelos sociais (FITZ, 2003, p. 15). Nesse caso, nota-se que, na maioria das vezes, as guerras são dotadas (pelas organizações e poderes sociais) de instrumentos ideológicos e político-econômicos que justifiquem tais ações (FITZ, 2003). Tendo em vista a importância da guerra no período estudado, nota-se que havia diversos princípios (morais e jurídicos) legitimadores e justificativos para a mesma - os códigos de comportamento, juntamente às noções do que eram ou não aceitáveis, fez que com que fossem cristalizadas as ideias de guerra justa e guerra santa. Sobre essa última, nota-se que há, diretamente, uma vinculação com os fundamentos religiosos - que incentivaram ou condenavam os conflitos, e os justificava (FITZ, 2003, p. 17).

Além dos tipos de guerras apresentadas anteriormente, havia duas outras formas de se fazer a guerra: a primeira, denominada de guerra constitutiva, envolvia tanto unidades políticas, quanto entidades soberanas - eram consideradas como naturais e envolviam fronteiras (reais ou imaginárias), assim como outras unidades políticas. Tais conflitos estavam relacionados à defesa do território e/ou buscavam garantir a soberania. A segunda forma diz respeito às guerras configurativas estritamente vinculadas às configurações territoriais, ou seja, resultavam de um antagonismo horizontal das relações de poder (relacionadas, portanto, às questões internacionais) (LATHAM, 2018).

Destaca-se que durante tal período, as sociedades europeias ocidentais demonstravam que “(...). Praticamente todas as manifestações humanas (...) práticas 


\section{O poder na Idade Média}

Andréa Grion Hungaro

econômicas, desde as instituições até os critérios de ordenação social, foram influenciadas pela guerra" (FITZ, 2003, p. 17). Entende-se, assim, que a guerra funcionava como mecanismo (estrutura) uma vez que sua presença era extremamente ampla.

Os tipos de guerra, assim como suas denominações, muitas vezes estão intrinsecamente relacionadas ao político-religioso, isso se dá pelo fato de que havia uma profunda conexão entre os valores religiosos e as diversas esferas sociais (FITZ, 2003, p.18). Considerando tais características, é importante ressaltar que há um fenômeno de síntese relacionado aos principais e mais conhecidos tipos de guerra, contudo, nota-se que mesmo havendo interligações, cada esfera continha sua própria lógica (FITZ, 2003, p. 18 - 19).

Ressalta-se que havia questionamentos sobre o fazer a guerra - os valores cristãos, em sua forma primitiva, condenavam toda guerra e violência. Ademais, outras questões começam a fazer parte da discussão sobre os conflitos, uma delas diz respeito à dúvida sobre a condenação daquele que se defende quando atacado. A partir de tal indagação, surgiu o termo e a ideia de guerra justa. (DEMURGER, 2007, p.40).

Tendo em vista que havia justificativas para as guerras, pode-se pensar, equivocadamente, que houvesse a prevalência de conflitos em relação à paz. Porém, a feudalidade não deve ser considerada desordem (anarquia), mas uma tentativa de se organizar a sociedade (DEMURGER, 2007, p.44). Em outras palavras, os conflitos, quando existentes, eram uma tentativa da manutenção da conjuntura do status quo por um lado, e, por outro, a tentativa de reorganizar tais poderes.

Nota-se que no período antecessor aos séculos XII e XIII, não havia exércitos 


\section{O poder na Idade Média}

A guerra como estrutura

permanentes. A atividade de guerra era temporária e momentânea, ainda que houvesse os chamados "profissionais" da guerra, esses seguiam e constituíam uma espécie de código militar (DEMURGER, 2007, p.265-266). Destaca-se, assim, que aqueles que guerreavam, se encontravam em subgrupos (infantaria, cavaleiros, e etc.) que muitas vezes disputavam por reconhecimento e status social, isso se refletia através dos regimentos militares - esses, durante a Idade Média Tardia ganharam um caráter institucional - que eram diferenciados de acordo com as hierarquias (de poder) existentes (KEEGAN, 1993).

Ressalta-se, ainda, que havia a coexistência de várias Ordens Militares, sendo, nesse caso, a de maior destaque para exemplificar a importância político-militar do período, a dos Templários (os primeiros a oferecer um modelo que serviu de influência para outras fundações e instituições relacionadas às questões bélicas). Tal exemplo é necessário uma vez que foi através de tal Ordem que, durante o Concílio de Troyes (em 1128), estabeleceu-se regras e fez-se menção a uma espécie de elogio a uma "nova cavalaria", que tinha, como principal aspecto, as obrigações do "Estado" monástico e militar (CONTAMINE, 1984, p.83). Nesse caso, nota-se que “(...). Na Europa monárquica (...) o regimento era um dispositivo para restringir a violência dos guerreiros e canalizá-las para os objetivos dos reis (...)" (KEEGAN, 1993).

A noção a respeito das guerras está estritamente ligada aos seus participantes diretos, ou seja, os exércitos e os cavaleiros. Destaca-se que esse último grupo constituía não apenas um meio profissional, mas também social - uma das grandes características da cavalaria, principalmente, em relação à hierarquia se dava, em muitos casos, por méritos pessoais, e não estava diretamente ligada ao estamento ao qual o combatente pertencia (CONTAMINE, 1984, p.86). Para compreender melhor o que eram tais ordens, deve-se ressaltar os significados que a palavra ordre pode ter - 


\section{O poder na Idade Média}

Andréa Grion Hungaro

desde um caráter mais sagrado até o conceito de grupo. Ou seja, poderia significar tanto status social quanto ordenação sacerdotal; poderia referir-se às ordens monástica e cavaleiresca. Dessa forma, é factível compreender toda essa acepção como relações de poder. Percebe-se, também, que em quase todos os casos, questões sobre o respeito e a fidelidade se davam ao soberano que outorgava à ordem (HUIZINGA, 2016, p.131).

Algumas ordens, sobretudo as militares, sobreviveram durante séculos após sua criação, possibilitando a participação em diversas atividades - como políticas e econômicas. Observa-se, assim, que o caráter ético das ordens era, muitas vezes, volátil - havia uma constante modelagem das características cavaleirescas existentes, fosse para um retorno aos princípios base, fosse para uma adaptação a moldes institucionais (CONTAMINE, 1984, p.97). Tais variações, indicativas às estruturas cavaleirescas, fez com que, muitas vezes, houvesse uma ruptura prática sobre quem participava de fato das guerras e conflitos, pois, a priori, apenas a nobreza poderia compor o corpo de cavaleiros. Contudo, nota-se alguns ideais tais como o de Philippe de Mézières (Ordre de la passion), em que todas as classes sociais seriam admitidas (HUIZINGA, 2016, p.130). Compreende-se, assim, que tanto os poderes laicos quanto os poderes religiosos consideravam a formação de ordens militares como um dos meios mais eficazes para se imporem. (CONTAMINE, 1984, p.97).

Nota-se que as unidades políticas detinham maior ou menor poder de acordo com a eficácia de controle, ou seja, através dos meios sócio-militares (MORILLO et al, 2009, p. 233) e da legitimação ligadas aos mesmos - compreende-se, assim, a importância que os diferentes níveis e hierarquias locais/sociais, estritamente ligados à guerra e a um sistema organizacional militar, expressavam em relação às questões de poder. Tendo em vista os distintos modelos e formas de funcionamento do 


\section{O poder na Idade Média}

A guerra como estrutura

sistema bélico, e em especial sobre as ordens militares, é necessário compreender a lógica de fidelidade (juramentos) existente. Esses, ainda que feitos pelas ordens militares, não se diferenciavam muito daqueles individuais. Sendo assim, a compreensão de como os mesmos de fato ocorriam e se encontravam socialmente só é melhor esclarecida quando observamos que seus diferentes tipos eram coexistentes em sociedade - englobando um jogo social elaborado, incorporando não apenas a coragem, a honra e os interesses de "Estado" (HUIZINGA, 2016, p.140-141).

Relações sociais e militarização: recrutamentos, obrigações e serviços.

Para entender a importância social e política que existia nas obrigações militares, é necessário observar que os poderes responsáveis por fazer a guerra se encarregavam de reunir os elementos militares - qualitativa e quantitativamente considerados mais viáveis economicamente e que garantissem a segurança. Considera-se que a maioria das contribuições relacionadas aos serviços e obrigações militares provinham do sistema feudal. Atenta-se, com isso, que cada poder deveria se apoiar em seus próprios recursos - tornando compreensível o fato de que cada um tivesse um conjunto de normas próprias (CONTAMINE, 1984, p.98).

Em relação às obrigações e serviços militares, ainda que os soberanos tivessem tais responsabilidades (juntamente com a manutenção dos costumes), sobretudo a respeito de questões territoriais, nas quais se acrescentaram, frequentemente, obrigações de caráter opressivo, havia, também, a possibilidade de substituir tais serviços/obrigações por pagamentos.

O caráter militar que o início do século XIII expunha, envolvia também as relações de poder da esfera horizontal, ou seja, as relações entre governantes, uma vez que previam a possibilidade de fazer a guerra, assim como a paz (CONTAMINE, 


\section{O poder na Idade Média}

Andréa Grion Hungaro

1984, p.101). Atenta-se a uma possível comparação entre o tamanho dos territórios e as prestações de serviços e obrigações militares - grandes regiões, assim como seus príncipes, respondiam positivamente às convocações reais com um grande número de contingentes militares (CONTAMINE, 1984, p.107).

Nota-se, ainda, o fato de que após o tratamento dos serviços militares obrigatórios, a quantidade de recursos econômicos utilizados para sua realização significava, essencialmente, a iniciativa dos poderes existentes, e não apenas uma forma de negociação (de mercado - oferta e demanda; empregadores e empregados). O pagamento feito àqueles que prestassem os serviços por meios de convocatórias e petições não era o suficiente para que se pudesse considerar a (trans)formação desses em mercenários (espécie de "soldado" sem vinculações políticas). No geral, aqueles que prestavam tais serviços “(...) chegavam ao local da convocatória em grupos familiares, feudais (...), seguiam lutando a serviço do 'soberano de direito' e as ordens (...) de seus senhores (...); em outras palavras, estavam imersos em suas estruturas sociais habituais. " (CONTAMINE, 1984, p.125).

Tem-se, então, o fato de que mesmo com um aumento no número de cidades e com o surgimento de um novo tipo de combatente, havia a manutenção da estrutura sociocultural com bases medievais, especialmente em relação aos recrutamentos esses, representavam tanto a pressão exercida pelos detentores de poder, quanto o laço existente entre eles e a sociedade (BLACK, 2007, p.179-181). Pode-se afirmar, portanto, que no tocante ao serviço militar, era importante o papel que a nobreza e a elite aristocrática ainda possuíam nas sociedades - seus comportamentos, assim como os da população eram vinculados às tradições (BLACK, 2007, p.186). Isso comprova que “(...) a guerra e as questões militares também compartilhavam processos políticos e sociais mais amplos (...)" (BLACK, 2007, p.186). Nesse sentido, 


\section{O poder na Idade Média}

A guerra como estrutura

ressalta-se que mesmo dentro dos grupos militares havia uma certa ordenação hierárquica, com base naqueles que detinham mais poder do que outros (CONTAMINE, 1984, p.90).

Tendo em vista a influência e a importância da imagem dos cavaleiros, nota-se a existência de diferentes denominações referentes a tal grupo. Destaca-se, portanto, as especificidades da ideia existente sobre os cavaleiros em cada região - as diversas categorias não correspondiam a nenhum padrão. As diferenciações (especialmente para o reconhecimento de um inimigo) muitas vezes eram feitas pela vestimenta (tipo de roupa, tipos e quantidades de armamentos), pelo cavalo (diferenciando, dentre os próprios cavaleiros, aqueles de origem nobre e de melhores posições hierárquicas de poder) e pela comitiva (mais ou menos numerosa) (CONTAMINE, 1984, p.163).

A diversificação da imagem dos cavaleiros pode ser explicada pelas diferenças econômicas e socioculturais de cada lugar (CONTAMINE, 1984, p.162). Junto a isso, destaca-se o fato de que as inovações bélicas não ocorreram igualitariamente e durante o mesmo tempo em toda a Europa Ocidental (sobretudo devido às distâncias e diferenças econômicas nas estruturas de poder) (CONTAMINE, 1984, p.180-183).

\section{Militarização e sociedade.}

Diante dos avanços econômicos, que ocorreram nas sociedades europeias a partir do século XIII, pode-se dizer que os recursos que um "Estado" possuía, assim como suas estruturas e instituições internas (governo e administração), serviram como chave para o desenvolvimento e a ampliação do sistema militar. Além das transformações bélicas, as organizações sociopolíticas também tiveram modificações - passaram a ter um caráter militar muito maior do que anteriormente. Pode-se afirmar que cada vez mais os "Estados" tentavam obter forças armadas adequadas 


\section{O poder na Idade Média}

Andréa Grion Hungaro

para suas ambições e temores (CONTAMINE, 1984, p.189), com isso, os aumentos dos gastos militares resultaram num maior número de recrutamento - fosse pelas convocações ou pelas contribuições com vinculação de vassalagem (CONTAMINE, 1984, p. 144).

Devido às transformações vividas pelas sociedades e pela economia, pode-se compreender que as relações militares e suas organizações também seriam alvos de mudanças, embora nunca drásticas demais, a ponto de romperem bruscamente com suas estruturas. Tem-se, assim, que no final do século XIV, o núcleo dos exércitos existentes na Europa Ocidental era constituído tanto por campanhas locais quanto por recrutas fixos. Esses seguiam os termos dos contratos de guerra (CONTAMINE, 1984, p.198). Junto a isso, tem-se que o sistema de conduta ("condotta") era caracterizado por uma mistura de dois comportamentos - um priorizava as atividades não condizentes com a utilização da força, enquanto o outro buscava apenas o lucro (mesmo que através da guerra). Dessa maneira, ainda que houvesse uma terceirização da guerra por alguns "Estados" e sobre os serviços militares, a presença de mercenários (grandes ou pequenos, de caráter individual ou não) fez com que aqueles que se utilizassem de tais grupos fossem chamados de "empresários militares" (CONTAMINE, 1984, p.201).

\section{Exércitos permanentes e a busca pela padronização militar.}

A constituição dos exércitos, assim como o número de seus participantes variavam e dependiam de cada região. Uma das diferenças em relação aos séculos anteriores se deu às roupas (uniformes) que, introduzidas no final do século XVII, tinham o significado de ordem e obediência hierárquica. Tais uniformes envolviam diretamente a nobreza, uma vez que se tem um aumento da participação de nobres a 


\section{O poder na Idade Média}

A guerra como estrutura

serviço do "Estado", assim como a sistematização de elos pessoais que vinculavam a nobreza à monarquia. Sendo assim, muitos nobres viam o seu papel dentro do serviço militar e, mais particularmente a liderança desse, como uma validação de suas relações sócio-políticas (de poder) (BLACK, 2007, p.176-177). Havia, então, por um lado uma sociedade/um sistema de caráter militar que possibilitava o uso e o fornecimento próprio/individual, e no qual as posições socioeconômicas diferenciavam uns e outros (mesmo com a existência de certo controle por parte dos poderes e pela sociedade para fazer uso de tais liberdades); e, ao mesmo tempo, existia o pressuposto, por parte do "Estado", de um controle total e exclusivo dos equipamentos, e da regulamentação para que houvesse uma padronização demonstrando, assim, a hierarquia e a articulação na relação dos poderes estruturais militares existentes. Atenta-se que a partir do século XII é possível observar que havia outras maneiras de diferenciação, inclusive entre as tropas, seguindo a hierarquia militar (CONTAMINE, 1984, p.239). Compreende-se, assim, que durante muito tempo os recrutamentos foram uma questão de oficiais aristocráticos em suas áreas de influência (BLACK, 2007, p.177) e que tal mecanismo se estendeu nas esferas políticosociais.

Uma vez que havia uma maior concentração dos poderes estatais, assim como as diferentes formas ligadas ao serviço militar, cabe afirmar que houve uma tendência em diminuir as punições locais, assim como o poder do ban senhorial ${ }^{3}$. Contudo, notase que, durante o século XV, ainda havia a existência de convocatórias feitas através

\footnotetext{
${ }^{3}$ Relativo ao direito de ban (derivado do latim bannum), termo específico inexistente em português. Em espanhol, o termo utilizado é "ban general" - relacionado ao senhorio banal, pode-se afirmar que nele se inclui o poder militar (obriga camponeses e vassalos ao serviço de hoste ou a prestações de serviços); o poder judicial (aplicação de taxas, multas e confisco de bens); o poder económico (obrigações de uso do moinho, forno ou taberna, aplicação de taxas sobre transações ou circulação de mercadorias, prestações em trabalho e etc.) (CONTAMINE, 1984, p.197).
} 


\section{O poder na Idade Média}

Andréa Grion Hungaro

do ban, demonstrando, assim, que quando necessário, até mesmo as formas mais antigas de prestação de serviço se mantinham vivas (CONTAMINE, 1984, p.197).

Ao analisar tal período, assim como a história da guerra (Europa Ocidental), compreende-se que já existiam guerreiros permanentes e fixos que podiam contribuir tanto para a manutenção das esferas locais quanto "estatais" (CONTAMINE, 1984, p.206). Pode-se, portanto, afirmar que os reinos/“Estados” eram um único corpo político sob o comando de uma autoridade temporal (ainda que os poderes espirituais tivessem determinada influência) - responsável pela garantia dos interesses defensivos comuns. A partir do final do século XII, a contextualização do período condizia ao crescente poder dos soberanos, tanto nos âmbitos internos/micros, quanto à crescente ordem geopolítica europeia (LATHAM, 2019). Observa-se que durante os séculos XIV e XV houve um aumento de servidores fixos, tal tendência se viu ampliada não apenas entre os reis e nobres, mas também dentro dos membros da Igreja. Nota-se que ao se falar em exércitos permanentes, o surgimento desses se deu, a priori, de maneira indireta e contida - para qualificar um exército como tal, era necessário a manutenção e a continuidade das unidades militares e o desejo por parte dos poderes em manter o serviço e a atividade de tais indivíduos em seus exércitos, independentemente do contexto (guerra e paz) (CONTAMINE, 1984, p.210).

Ressalta-se, porém, que não é possível considerar, de fato, uma introdução dos exércitos permanentes sem que antes todos que estivessem envolvidos (meios dirigentes e o conjunto populacional) considerassem tal existência como natural. Isso dependia diretamente das relações de poderes existentes no nível doméstico, assim como da conjuntura política internacional, em outras palavras, a centralização das forças armadas, tendia para que as chamadas "guerras do reino" e as "guerras do rei" 


\section{O poder na Idade Média}

A guerra como estrutura

fossem compreendidas como sinônimos (CONTAMINE, 1984, p.211). Junto a isso, durante os séculos XVII e XVIII, houve, de fato, um maior controle e poder territorial a limitação geográfica em muitas regiões, especialmente de fronteiras, era tal que o exército era uma das poucas soluções para a manutenção da ordem (BLACK, 2007, p.166).

Ao considerar a guerra como estrutura, dependente das conjunturas políticas locais e internacionais, pode-se compreender que durante o período final da Idade Média, assim como da Idade Média Tardia, a busca pela manutenção das relações de poderes em uma esfera local e a tentativa em se estabilizar os espaços geográficos dominados possibilitaram a compreensão de que da mesma maneira que tais sociedades obtinham um maior caráter militar, o anseio pela paz era igualmente existente, especialmente (por parte das e) nas relações horizontais de poder. Por fim, ressalta-se que o papel da guerra, assim como o papel do governante diz respeito a uma legitimação moral do poder (SENELLART apud ALMEIDA, 2010, p.69).

\section{O Sistema Internacional e a Paz de Vestfália.}

Para que se possa compreender o mundo medieval, assim como a ideia de que o conceito de internacionalização seja mais antigo do que aparenta, é preciso levar em consideração a complexidade e a percepção de que não existe necessariamente uma linearidade e um desenvolvimento contínuo. (MARKS apud DEKKER \& WERNER, p.10).

Ao pensar as relações existentes no medievo, deve-se compreender que, para além de trocas comerciais (integrações socioculturais), havia um sistema políticoestrutural complexo responsável pela noção de existência de certa ordem 


\section{O poder na Idade Média}

Andréa Grion Hungaro

internacional e doméstica - as relações sociais (de poder) existentes são parte de um sistema/ordem político-jurídico. Nota-se que durante tal período coexistiam diversos sistemas jurídicos (romano, canônico, germânico e etc.), juntamente com a ordenação jurídica feudal, e a esfera macro das relações de poder (o sistema internacional) (ARAUJO, 2012).

Considerando-se o contexto político-econômico e cultural dos séculos XVII e $\mathrm{XVIII}$, especialmente, nos aspectos militares e governamentais, pode-se afirmar que quaisquer ações eram observadas e acompanhadas por outros poderes e potências, permitindo com que gozassem de liberdade de manobra no âmbito das Rl e, acentuando a pressão de preparo e estrutura militar (BLACK, 2007, p.172). Tendo em vista a existência de um sistema múltiplo de "Estados", assim como a complexidade interna, questões ligadas à soberania são, normalmente, mal interpretadas - tem-se a ideia de que tais sociedades poderiam ser definidas como "feudal": as soberanias permaneceram atreladas à dependência mútua entre a Coroa e o privilégio das classes (TESCHKE, 2006, p.538).

Esse "novo" olhar para o sistema internacional, no entanto, não anula a forma com que os soberanos/governantes atuavam (mudou-se a quantidade de poder e autoridade obtida). Tal aumento não influenciou o funcionamento político de coexistência entre e inter "estados" - mantinha-se não só autoridades distintas (e até mesmo sobrepostas), mas também a (co)existência de outras formas político-culturais (DEKKER \& WERNER, 2004, p.26).

A noção de um "mundo internacional", muito utilizada atualmente, não é, de fato, uma novidade, especialmente, no tocante ao Direito Internacional, que reconheceu, há tempos, que os "Estados" “(...) não são impermeáveis e que a 


\section{O poder na Idade Média}

A guerra como estrutura

'intensificação das relações (...) mundiais (...) aproximava distintos lugares, de forma com que acontecimentos locais eram moldados por eventos que aconteciam em locais muito distantes (...)"' (GIDDENS apud DEKKER and WERNER, 2004, p. xiii).

Para que compreender melhor esse campo de estudos, deve-se entender o vínculo existente entre o medievo e o conceito de internacionalização dado pelo mundo pós-Vestfália, uma vez que é após tal Tratado em 1648 que surge um outro olhar para compreender as RI - políticas domésticas e externas entre "países" soberanos. Contudo, destaca-se que “(...) semelhante consenso é (...) discutível, podendo (...) afirmar-se que o evento de Vestfália é talvez 'um dos mais distorcidos por aqueles que estudam o <<internacional>>"' (FREIRE apud MOITA, 2012, p.19). Considerando o contexto em que tal acordo é firmado, assim como as características gerais, pode-se afirmar que “(...) os Tratados de Paz de Vestfália não marcam uma ruptura em direção às regras e normas (...); apenas formalizaram a lógica (...) do sistema de 'Estados' (...)" (TESCHKE, 2006, p. 539).

Ao considerar que tais características, especialmente, vinculadas à ideia de Estado-Nação e de soberania, não foram inauguradas com Vestfália, ressalta-se que a Europa Ocidental não era, em muitos aspectos, homogênea. Ou seja:

(...). Se nesta época as sociedades (...) caminhavam no sentido de uma centralização do poder, (...) o Estado-nação nasce nuns casos muito antes, noutros casos muito depois (...). Em certos (...) processos, a nação precede o Estado, no sentido em que uma comunidade, já possuidora de identidade própria, se dota da forma de organização política (...). Noutros processos, porém, (...) é o inverso (...) (MOITA, 2012, p. 26).

Ademais, nota-se que, em relação ao modelo vigente, mesmo após 1648, esse 


\section{O poder na Idade Média}

Andréa Grion Hungaro

era caracterizado não por um sistema estatocêntrico, mas pela coexistência de

(...) Estados nacionais razoavelmente consolidados (...), a sobrevivência do Sacro Império que manteve muitas das suas estruturas, e (...) outras unidades políticas gozando de diferentes graus de autonomia (...): (...), Condados, (...), Principados, Ducados, (...), Reinos, (...), Abadias, Bispados, (...), Marquesados (...) (MOITA, 2012, p. 35).

A análise sobre as características que moldaram tal período, em seus diversos campos, e sobretudo no fim da guerra, demonstram uma série de equívocos existentes em muitas áreas de conhecimento. Tendo em vista a complexidade do período, pode-se afirmar que o campo das RI não estaria isento de tais falhas. Essas, estão ligadas a consideração de que Vestfália inaugura o Estado laico e a utilização do Equilíbrio de Poder (ZIELONKA, 2013, p. 7). Sobre esse último nota-se que já havia, há tempos, coligações e alianças que tentassem impedir a hegemonia de determinado “Estado" (MOITA, 2012, p.27).

Sobre a guerra como estrutura, pode-se citar autores como Mark Potter, que afirma que a guerra e seus desafios impactaram o desenvolvimento político, porém não no sentido "moderno", como é frequentemente assumido (POTTER apud TESCHKE, 2006, p. 557). Compreende-se, portanto, que tal período não foi isento de mudanças, tanto em relação à guerra, quanto no âmbito político; contudo, tais alterações não podem ser consideradas rupturas com as estruturas existentes.

\section{Conclusão}

Ao analisar a guerra durante o final da Idade Média e da Idade Média Tardia foi possível observar que diferentemente do que se costuma pensar, tanto o período que é caracterizado como Idade Média, quanto o período denominado Moderno, não são exatamente fases distintas, mas a continuação (ainda que com algumas 


\section{O poder na Idade Média}

A guerra como estrutura

transformações) dos costumes sociais, políticos e militares que regiam a Europa Ocidental.

Nota-se que o período medieval foi composto por diversas relações e divisões de poderes que se mantiveram durante muito tempo. Contudo, isso não significa que não houve mudanças, especialmente a respeito do fazer a guerra e nos espaços de poder existentes. Tal período, embora complexo por suas conjunturas domésticas e internacionais, possuía em sua estrutura bélica um forte vínculo político. Nesse sentido, é possível afirmar que as relações de poder existentes no âmbito militar (assim como nas demais esferas político-econômicas) podem ser caracterizadas tanto por questões micro (internas aos grupos de combatentes) quanto por macros. Observa-se, também, a existência de mais de uma ordenação quando referente às relações de poder - verticais e/ou horizontais; essas dizem respeito àqueles capazes de reunir forças militares em esferas locais, e aos responsáveis pela imposição e conquista de um papel dentro da ordem geopolítica.

O presente artigo propôs uma compreensão de que o papel da guerra, assim como o período como um todo, englobava várias complexidades, não só pelo fato de que era a guerra (e sua estrutura militar) a responsável pela manutenção de determinados poderes, como era, também, responsável pelas mudanças e transformações dos mesmos (nas diferentes esferas). Dessa maneira, para entender melhor as relações de poder existentes de forma geral, deve-se ter em mente que a estrutura relacionada às guerras está estritamente ligada às conjunturas sistêmicas (domésticas e internacionais), o que possibilita uma melhor compreensão dos funcionamentos sociais, políticos e econômicos do mundo medieval.

Esse estudo procura esclarecer o fato de que a utilização de alguns conceitos 


\section{O poder na Idade Média}

Andréa Grion Hungaro

"fixos" e definições em sua forma mais pura (como por exemplo a ideia de poder weberiana, assim como a ideia de estamentos/ordens medievais) não são autossuficientes para uma análise completa quando aplicados à história e suas questões sócio-político-culturais. Ou seja, é necessário a combinação de vários conceitos e elementos para que se possa compreender determinado período como um todo - e em especial, a Idade Média.

Por fim, buscou-se apresentar que, já naqueles períodos, os Tratados assinados tinham valor de leis - o cumprimento dos acordos estava vinculado à honra. Nesse sentido, é possível confirmar, não apenas a presença do Direito Internacional entre as relações político-militares-sociais do período, mas, também, de um Sistema Internacional (mesmo que distinto do que é conhecido atualmente). Dessa forma, apresentou-se, de maneira geral, as conjunturas internas e externas da Europa Ocidental durante a Idade Média Tardia ao demonstrar um quadro amplo. Evidenciou-se, assim, a impossibilidade de compreender um assunto que envolve diferentes aspectos de forma isolada e independente - as consequências históricas (políticas, militares, sociais, territoriais e culturais) estão interligadas às diferentes conjunturas e esferas.

\section{Referências Bibliográficas.}

ALMEIDA, Neri de Barros. A Idade Média entre o "poder público" e a "centralização política", itinerários de uma construção historiográfica. Belo Horizonte: Varia Historia, 2010, vol.26, n43.

ARAUJO, Luciana Souza. Entre o medieval e o moderno: rupturas e continuidades. o nominalismo medieval e o jusnaturalismo contratualista. Uberlândia: XXI Encontro Nacional do CONPEDI. 2012.

BALANDIER, Georges. O poder em cena. Brasília: Editora Universidade de Brasília, 


\section{O poder na Idade Média}

A guerra como estrutura

1982.

BLACK, Jeremy. European warfare in a global contexto, 1660-1815. Canada: Routledge, 2007.

BOURDIEU, Pierre. O poder simbólico. Rio de Janeiro: Editora Bertrand Brasil, 1989.

BRAUDEL, Fernand. Escritos sobre a história. São Paulo: Perspectiva, 2007.

CONTAMINE, Philippe. La guerra en la edad media. Barcelona: Editorial Labor S.A, 1984.

CORTÁZAR, José Ángel Garcia de. Elementos de definición de los espacios de poder em la edad media. Universidad de Cantabria. 2002.

DEKKER, Ige; WENER, Wouter. Governance and international legal theory. Leiden: Springer Science + Business Media Dordrecht, 2004.

DEMURGER, Alain. Os templários: uma cavalaria cristã na idade média. Rio de Janeiro: DIFEL, 2007.

FITZ, Francisco. La edad media guerra e ideología - justificaciones religiosas y jurídicas. Madrid: Sílex, 2003.

FOSSIER, Robert. Fidélité. In: GAUVARD, C.; DE LIBERA, A.; ZINK, M.. Dictionnaire du Moyen Âge. Paris: PUF, 2002.

GOFF, Jacques Le. Para uma outra idade média. Petrópolis: Vozes, 2014.

GÓMEZ, Mario Lafuente. Amistad y poder entre la baja nobleza aragonesa del trescientos. Santander: PUbliCan, Ediciones de la Universidad de Cantabria, D.L. 2012.

HOBSBAWN, Eric. A era das revoluções. São Paulo: Paz e Terra Ltda, 2010.

HUIZINGA, Johan. O outono da idade média. São Paulo: Cosacnaify, 2016.

KEEGAN, John. Uma história da guerra. São Paulo: Editora Schwarcz Ltda. Companhia de Bolso, 1993.

LATHAM, Andrew. Medieval geopolitics: the two types of warfare in medieval 


\section{O poder na Idade Média}

Andréa Grion Hungaro

Europe. 2018. Disponível em: < https://www.medievalists.net/2018/03/medievalgeopolitics-two-types-warfare-medieval-europe/ >. Acesso em: 26 de Julho de 2020.

LATHAM, Andrew. Questions of power and authority between Church and State. 2019. Disponível em: < https://www.medievalists.net/2019/04/power-authoritychurch-state/>. Acesso em: 26 de Julho de 2020.

MOITA, Luís. Uma releitura crítica do consenso em torno do "sistema vestefaliano". E- Journal of International Relations, vol. 3, nº 2. 2012.

MORILLO, Stephen; BLACK, Jeremy; LOCOCO, Paul. War in the world history society, technology, and war from ancient times to the present. Vol. 1. To 1500. New York: Mc Graw Hill, 2009.

ROSHCHIN, Evgeny. The concept of friendship: from princes to States. European University at St. Petersburg. European Journal of International Relations. SAGE Publications and ECPR- European Consortium for Political Research, vol. 12(4). 2006.

TESCHKE, Benno. Debating 'the myth of 1648': State formation, the Interstate System and the emergence of capitalism in Europe - a Rejoinder. Sussex. University of Sussex. 2006.

ZIELONKA, Jan. The international system in Europe: westphalian anarchy or medieval chãos?. Oxford: Journal of European Integration, vol.35, n.1, p.1-18, 2013 